\title{
Avaliação da Demanda Bioquímica de Oxigênio (DBO) como parâmetro de poluição na Bacia Hidrográfica do Córrego Caçula - SP
}

\author{
Biochemical Oxygen Demand (BOD) as a pollution parameter in the Córrego Caçula \\ basin - SP
}

la demanda bioquímica de oxígeno (BOD) a la corriente de parámetro contaminación en la cuenca más joven - SP

Letícia de Oliveira Manoel Doutoranda em Ciências Biológicas, UNESP/IBB, Brasil. leticia.is@gmail.com

lara Bernardi Sant'Anna Mestre em Engenharia Civil, UNESP, Brasil. eng.iarabernardi@gmail.com

Sérgio Luís de Carvalho Professor Doutor, UNESP/FEIS, Brasil sl.carvalho@unesp.br 


\title{
Fórum Ambienta

RESUMO

Uma das maneiras de avaliar o grau de poluição de um corpo hídrico é a quantificação da matéria orgânica existente, ela é uma característica de primordial importância, sendo a causadora do principal problema de poluição das águas: o consumo do oxigênio dissolvido pelos microrganismos nos seus processos metabólicos de utilização e estabilização da matéria orgânica. Sua introdução em corpos hídricos se dá de maneira natural e antrópica, a resolução CONAMA estabelece um valor de DBO não superior a $5 \mathrm{mg} \cdot \mathrm{L}^{-1}$. Portanto, objetivou-se com o presente trabalho avaliar as concentrações de DBO na Bacia Hidrográfica córrego Caçula no município de Ilha Solteira- SP, durante o período de maio/12 a abril/13, em cinco pontos de amostragem. Foi utilizado o Método das Diluições, Incubado a 20 ㄷ, 5 dias, de acordo com os Métodos para as Análises de Águas Potáveis e Residuárias - Standard Methods for Examination of Water and Wastewater, e comparadas com a Resolução CONAMA no 357/2005. Com base nos resultados obtidos, conclui-se que a bacia hidrográfica do córrego Caçula, embora tenha recebido cargas pontuais de poluentes, manteve-se de maneira geral, em um nível aceitável de qualidade durante o período amostral, acredita-se que o corpo hídrico estudado apresente uma boa capacidade de autodepuração.

PALAVRAS-CHAVE: Recursos hídricos. Drenagem urbana. Autodepuração.

\begin{abstract}
One of the ways of assessing the degree of pollution of a water body is the quantification of the existing organic matter, it is a characteristic of primordial importance, being the cause of the main problem of water pollution: the consumption of dissolved oxygen by the microorganisms in their processes utilization and stabilization of organic matter. Its introduction into water bodies occurs naturally and anthropically, the CONAMA resolution establishes a $B O D$ value of no more than $5 \mathrm{mg} \cdot \mathrm{L}^{-1}$. Therefore, the objective of this work was to evaluate the concentrations of $B O D$ in the Caçula Basin in the municipality of Ilha Solteira-SP, from May / 12 to April / 13, at five sampling points. The Dilutions Method, Incubated at 20C, 5 days, according to the Methods for the Analysis of Drinking Water and Wastewater - Standard Methods for Examination of Water and Wastewater, and compared to CONAMA Resolution $n=357 / 2005$. Based on the results obtained, it is concluded that the catchment area of the Caçula stream, although it received punctual loads of pollutants, was generally maintained at an acceptable level of quality during the sample period, it is believed that the water body studied has a good self-purification ability.
\end{abstract}

KEY WORDS: Water resources. Urban drainage. Autodepuration.

\section{RESUMEN}

Una de las maneras de evaluar el grado de contaminación de un cuerpo hídrico es la cuantificación de la materia orgánica existente, es una característica de primordial importancia, siendo la causante del principal problema de contaminación de las aguas: el consumo del oxígeno disuelto por los microorganismos en sus procesos metabólicos de utilización y estabilización de la materia orgánica. Su introducción en cuerpos hídricos se da de manera natural y antrópica, la resolución CONAMA establece un valor de DBO no superior a $5 \mathrm{mg} \cdot \mathrm{L}^{-1}$. Por lo tanto, se objetivó con el presente trabajo evaluar las concentraciones de $D B O$ en la Cuenca Hidrográfica arroyo Caçula en el municipio de Ilha Solteira-SP, durante el período de mayo / 12 a abril / 13, en cinco puntos de muestreo. Se utilizó el Método de las diluciones, Incubado a $20^{\circ} \mathrm{C}$, 5 días, de acuerdo con los Métodos para los Análisis de Aguas potables y residuales Standard Methods for Examination of Water and Wastewater, y comparadas con la Resolución CONAMA no 357/2005. Con base en los resultados obtenidos, se concluye que la cuenca hidrográfica del arroyo Caçula, aunque ha recibido cargas puntuales de contaminantes, se mantuvo de manera general, en un nivel aceptable de calidad durante el período muestral, se cree que el cuerpo hídrico estudiado presenta una buena capacidad de autodepuración.

PALABRAS CLAVE: Recursos hídricos. Drenaje urbano. Autodepuración. 


\section{Periódico Eletrôutico}

\section{INTRODUÇÃO}

A água está se tornando um elemento cada vez mais escasso, tanto em termos qualitativos como quantitativos. Isso vem acontecendo devido ao crescimento urbano industrial que apresenta uma demanda crescente de água e aumento da produção de resíduos, ao manejo inadequado na atividade agrícola e pecuária, à falta de planejamento e gestão dos recursos hídricos (QUEIROZ et al., 2010).

A qualidade da água está relacionada ao tipo de uso e deve ser mantido um constante monitoramento de suas qualidades físicas, químicas e biológicas a fim de impedir danos ao sistema aquático e à saúde humana (SARDINHA et al., 2008).

O monitoramento ambiental em bacias hidrográficas procura analisar aspectos relevantes que permitam caracterizar as mudanças que ocorrem no uso e ocupação do solo, tornando possível avaliar os efeitos das atividades humanas sobre os ecossistemas (BERTOSSI et al., 2013). A importância do monitoramento da qualidade dos recursos hídricos em uma bacia reside no fato de que, a partir das informações coletadas, se pode inferir sobre a condição ambiental da bacia hidrográfica como um todo (QUEIROZ et al., 2010).

Uma das maneiras de avaliar o grau de poluição de um corpo hídrico é a quantificação da matéria orgânica existente, ela é uma característica de primordial importância, sendo a causadora do principal problema de poluição das águas: o consumo do oxigênio dissolvido pelos microrganismos nos seus processos metabólicos de utilização e estabilização da matéria orgânica (VON SPERLING, 1996).

Utilizam-se normalmente métodos indiretos para a quantificação da matéria orgânica, ou do seu potencial poluidor. Nesta linha, existem duas principais categorias de medição: a medição de consumo de oxigênio, por meio da Demanda Bioquímica de Oxigênio (DBO) ou Demanda química de oxigênio (DQO) e a medição de carbono orgânico total (COT). A DBO é o parâmetro tradicionalmente mais utilizado (VON SPERLING, 2005).

A Demanda Bioquímica de Oxigênio (DBO) sempre foi caracterizada como um dos principais parâmetros de qualidade da água. É definida como a quantidade de oxigênio necessária para oxidar a matéria orgânica biodegradável, sob condições aeróbicas, ou seja, avalia a quantidade de oxigênio dissolvido (OD) em mg. $\mathrm{L}^{-1}$ de $\mathrm{O}_{2}$, que será consumido pelos organismos aeróbios ao degradarem a matéria orgânica (LIMA, IZARIO FILHO, CHAVES, 2006).

Em águas naturais, a DBO representa a demanda potencial de oxigênio dissolvido que poderá ocorrer devido à estabilização dos compostos orgânicos biodegradáveis, o que poderá reduzir os níveis de oxigênio nas águas abaixo dos exigidos pela vida aquática. É um parâmetro imprescindível nos estudos de autodepuração dos cursos d'água e composição dos índices de qualidade dos mesmos (CETESB, 2008).

O objetivo do trabalho foi avaliar a poluição da água na bacia hidrográfica do córrego Caçula, no município de Ilha Solteira-SP, utilizando como parâmetro a concentração de Demanda Bioquímica de Oxigênio (DBO). 


\section{MATERIAL E MÉTODOS}

Realizou-se 12 campanhas com periodicidade mensal (maio/2012 a abril/2013), em cinco pontos amostrais, localizados na Bacia Hidrográfica do Córrego Caçula, no município de Ilha Solteira, região noroeste do Estado de São Paulo (Figura 1).

Figura 1. Mapa da Bacia Hidrográfica do Córrego Caçula, localizada no município de Ilha Solteira - SP.

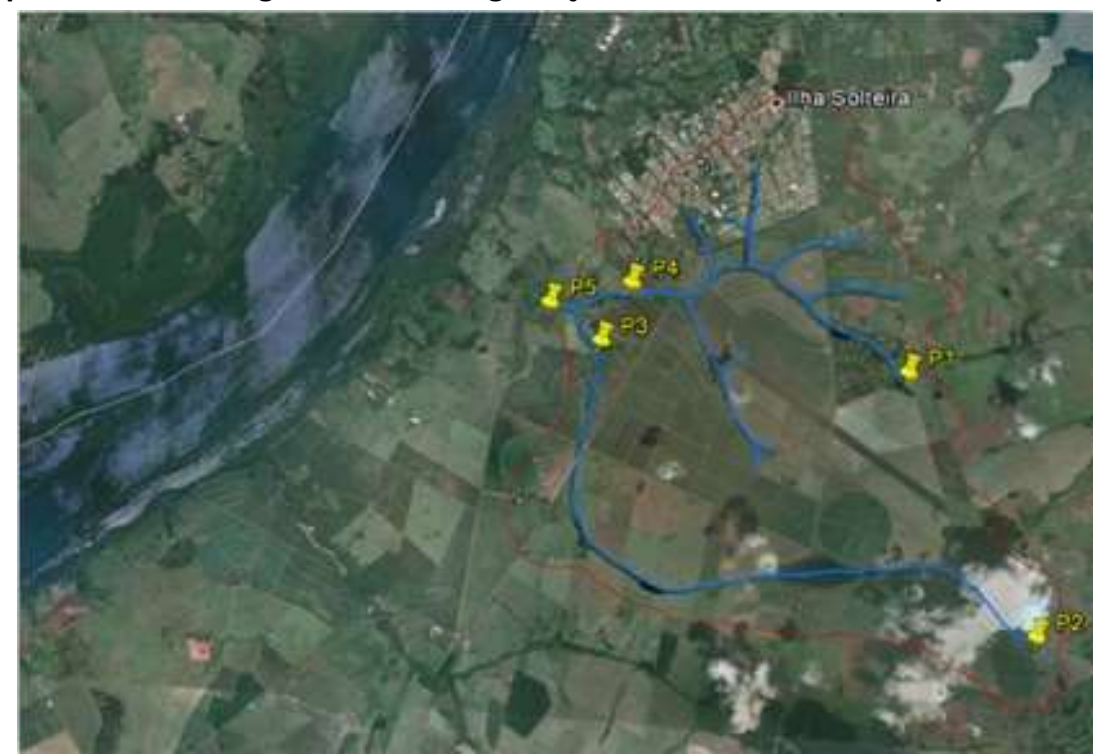

Fonte: GOOGLE EARTH, 2011.

Para averiguar os fatores que influenciam a qualidade da água na Microbacia Hidrográfica do Córrego Caçula, e caracterizar a influência dos diversos usos e ocupação do solo que compreende a área de estudo, foram propostos cinco pontos de amostragem, distribuídos por toda a microbacia, compreendendo desde suas principais nascentes até sua foz no Rio Paraná levando-se em conta a acessibilidade ao local (Tabela 1).

Tabela 1: Pontos de amostragem, coordenadas geográficas, localização e uso predominante do solo.

\begin{tabular}{ccccc}
\hline $\begin{array}{c}\text { PONTOS } \\
\text { AMOSTRAIS }\end{array}$ & LATITUDE & LONGITUDE & LOCALIZAÇÃo & $\begin{array}{c}\text { USO } \\
\text { PREDOMINANTE DO } \\
\text { SOLO }\end{array}$ \\
\hline $\mathbf{1}$ & $20^{\circ} 27^{\prime} 25.4^{\prime \prime}$ & $51^{\circ} 18^{\prime} 33.7^{\prime \prime}$ & Nascente do córrego do Ipê & Agrícola e Urbano \\
\hline $\mathbf{2}$ & $20^{\circ} 29^{\prime} 31.0^{\prime \prime}$ & $51^{\circ} 17^{\prime} 17.4^{\prime \prime}$ & Nascente do córrego das & Lagoas \\
\hline $\mathbf{3}$ & $20^{\circ} 27^{\prime} 05.3^{\prime \prime}$ & $51^{\circ} 21^{\prime} 45.8^{\prime \prime}$ & Foz do córrego das lagoas & Agrícola \\
\hline $\mathbf{4}$ & $20^{\circ} 27^{\prime} 05.2^{\prime \prime}$ & $51^{\circ} 21^{\prime} 46.8^{\prime \prime}$ & Foz do córrego do lpê & Agrícola e Urbano \\
\hline $\mathbf{5}$ & $20^{\circ} 27^{\prime} 08.9^{\prime \prime}$ & $51^{\circ} 21^{\prime} 53.4^{\prime \prime}$ & Foz do córrego Caçula & Agrícola e Pecuária \\
\hline
\end{tabular}

As coletas foram realizadas no período matutino, utilizando garrafas de polietileno de dois litros higienizadas com água ionizada, as amostras foram preservadas seguindo os procedimentos recomendados na NBR 9898/97. 


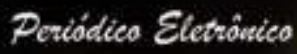

Para a análise da Demanda Bioquímica de Oxigênio (DBO) foi utilizado o Método das Diluições, Incubado a $20^{\circ} \mathrm{C}, 5$ dias, de acordo com os Métodos para as Análises de Águas Potáveis e Residuárias - Standard Methods for Examination of Water and Wastewater, e comparadas com a Resolução CONAMA no 357/2005.

As amostras de água foram encaminhadas em caixas térmicas contendo gelo para o Laboratório de Saneamento do Departamento de Engenharia Civil da Faculdade de Engenharia de Ilha Solteira (UNESP) para a realização das análises.

\section{RESULTADOS E DISCUSSÃO}

A DBO é uma variável muito importante para se avaliar a qualidade das águas e indicar lançamento de efluentes. Ela representa o quanto é necessário de oxigênio para depurar a matéria orgânica presente nas águas. Dessa forma, para um ambiente em equilíbrio espera-se que haja altos valores de OD e baixos valores de DBO.

Na Figura 2 é possível observar que, no período estudado, os valores de DBO apresentaram-se dentro do limite estabelecido pela legislação, para corpos d'água de classe 2 , que é $5 \mathrm{mg} \cdot \mathrm{L}^{-1}$, exceto para os meses de setembro nos Pontos (4 e 5) e novembro no Ponto 2.

Vale salientar, que no período chuvoso as concentrações de DBO foram inferiores aos resultados obtidos para o período seco. Isso ocorreu, provavelmente, devido à diluição promovida pelo período chuvoso e a baixa vazão dos Córregos na seca, onde a atividade autodepurativa é diminuída neste período. Resultados semelhantes foram encontrados por Vasco et al. (2011), Barros e Souza (2012), Silva, Faria \& Moura (2017).

Figura 2. Concentrações de Demanda Bioquímica de Oxigênio (DBO) nos pontos de amostragem na bacia hidrográfica do córrego Caçula, município de Ilha Solteira - SP.

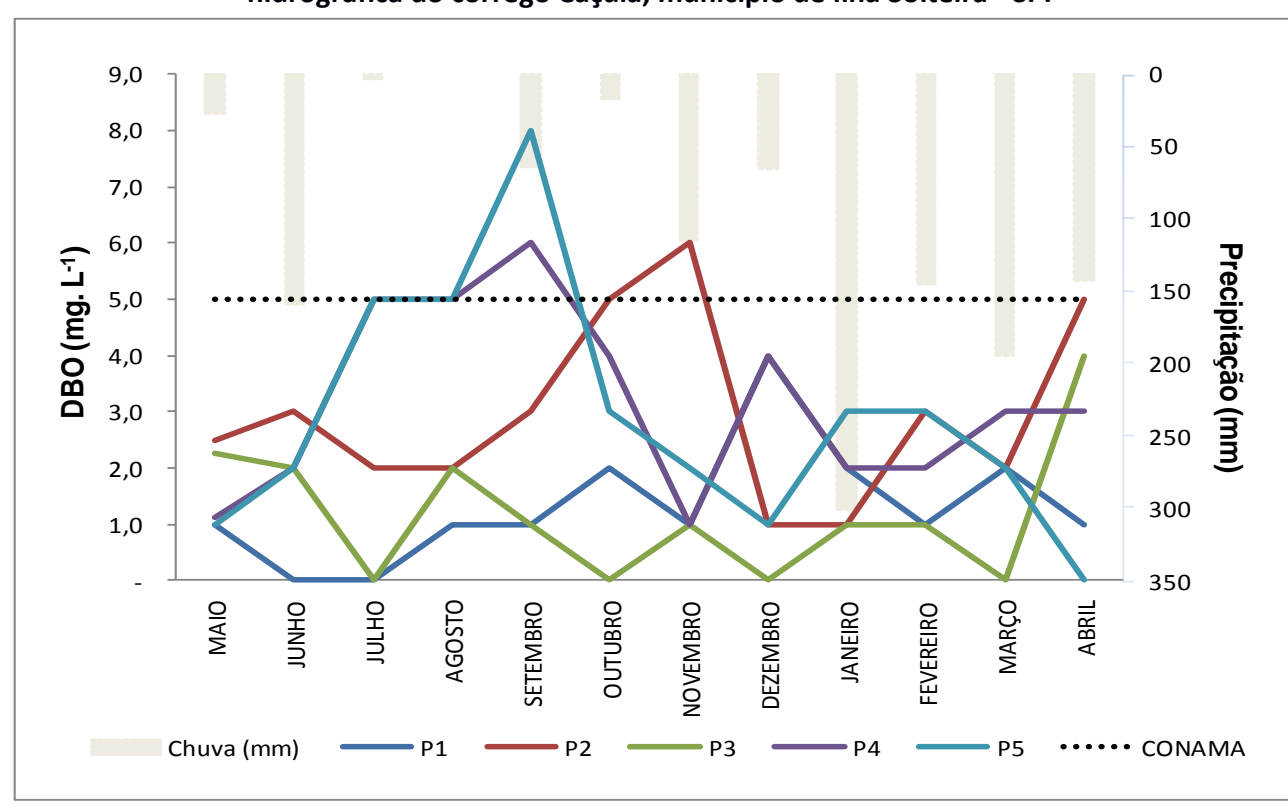

Fonte: Próprio autor 


\section{Periódica Eletrônica}

\section{Fórum Ambienta? \\ e \\ - 5 .}

De maneira geral, pode-se dizer que os níveis de DBO sofreram pequena alteração condicionada principalmente ao ciclo hidrológico, apresentando valores baixos no período de cheia e elevados no período de seca.

Em campo, observou-se alguns impactos antrópicos, bem como, lançamentos clandestinos de matéria orgânica, drenagem pluvial, decomposição da vegetação invasora e ribeirinha ao longo do curso hídrico, além dos extravasamentos das bombas de recalque referente ao esgoto doméstico municipal, prováveis causadores do aumento da matéria orgânica, podendo justificar os resultados obtidos (Figura 3).

Figura 3. Decomposição da vegetação ribeirinha (A) no ponto 2, lançamento de esgoto clandestino (B e C) , drenagem pluvial (D) localizado a montante dos Pontos 4 e 5 , na bacia hidrográfica do córrego Caçula, Ilha Solteira, SP.

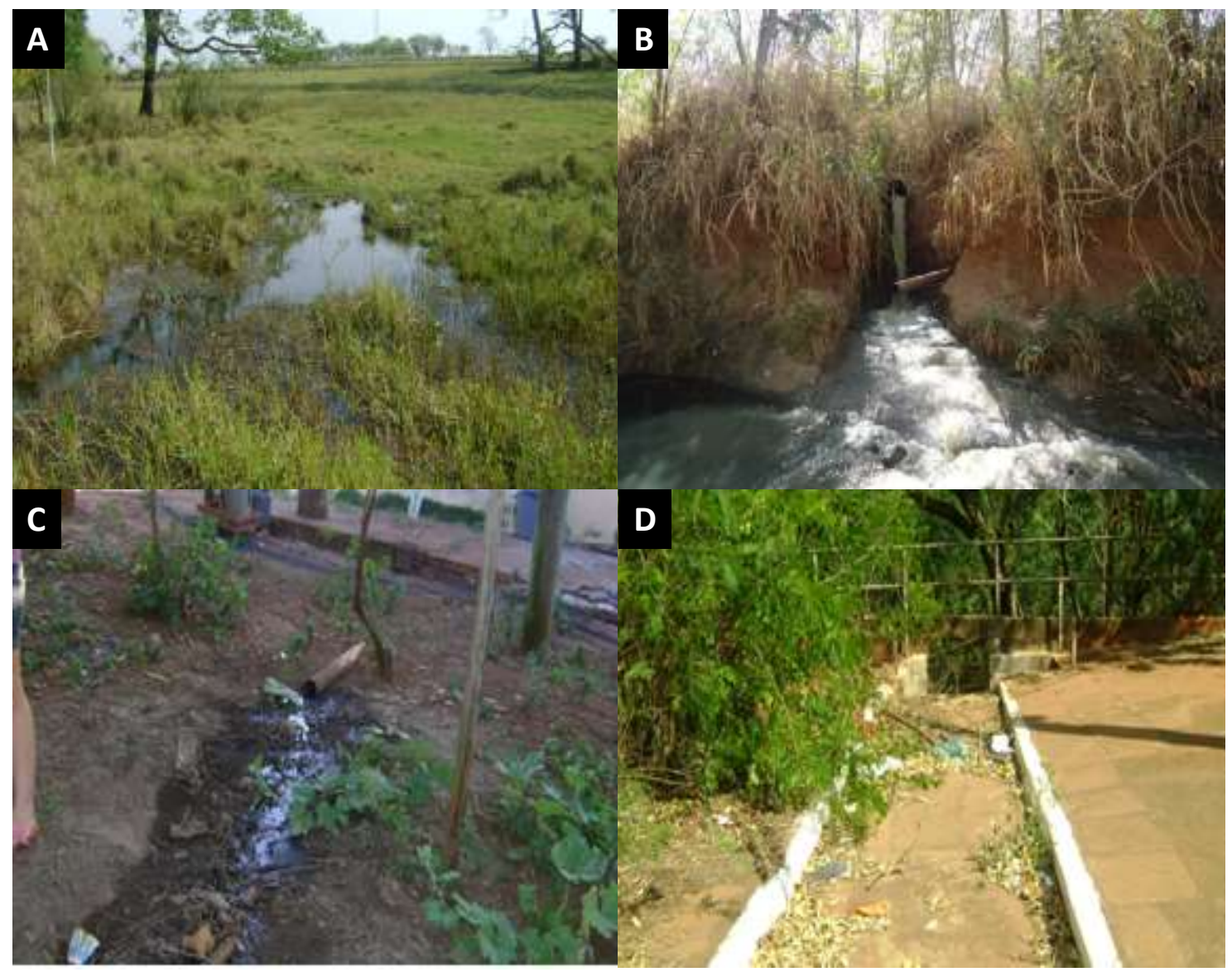

Fonte: MANOEL, 2013

Quando o esgoto clandestino é lançado in natura nos corpos d'água, isto é, sem receber um prévio tratamento, dependendo da relação entre as vazões de esgoto lançado e do corpo receptor, pode-se esperar, na maioria das vezes, sérios prejuízos à qualidade da água.

Segundo Sardinha et al. (2008) além de um visual desagradável, pode haver um declínio dos níveis de oxigênio dissolvido, afetando a sobrevivência dos seres de vida aquática, exalação de gases mal cheirosos e possibilidade de contaminação de animais e seres humanos pelo consumo ou contato com essa água, dentre outros aspectos. 


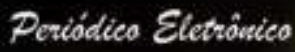

Neste sentido, o ecossistema de um corpo d'água antes do lançamento de despejos encontrase usualmente em um estado de equilíbrio. Após a entrada da fonte de poluição, o equilíbrio entre as comunidades é afetado, resultando numa desorganização inicial, seguida por uma tendência posterior à reorganização (SARDINHA et al.,2008).

Segundo Von Sperling (1996) a autodepuração pode ser entendida como um fenômeno de sucessão ecológica, onde o restabelecimento do equilíbrio no meio aquático é feito por mecanismos essencialmente naturais, havendo uma seqüência sistemática de substituições de uma comunidade por outra, até que a comunidade estável se estabeleça em equilíbrio com as condições locais.

\section{CONCLUSÃO}

Conclui-se que a bacia hidrográfica do córrego Caçula, embora tenha recebido cargas pontuais de poluentes, manteve-se de maneira geral, em um nível aceitável de qualidade durante o período amostral, acredita-se que o corpo hídrico estudado apresente uma boa capacidade de autodepuração.

\section{REFERÊNCIAS BIBLIOGRÁFICAS}

AMERICAN PUBLIC HEALTH ASSOCIATION - APHA - American Water Works Association - AWWA, Water Environmental Federation - WEF. Standard Methods for the Examination of Water and Wastewater. 20 ed. Washington, 1998.

BARROS, R. V. G., SOUZA, C. A. Qualidade do recurso hídrico do Córrego André, Mirassol D'Oeste. Revista Brasileira de Ciências Ambientais, São Paulo, n. 24. p. 1-16. jun. 2012.

BERTOSSI, A. P. A., CECÍLIO, R. A., NEVES, M. A., GARCIA, G. O. Qualidade da água em microbacias hidrográficas com diferentes coberturas do solo no sul do Espírito Santo. Revista Árvore, Viçosa - MG, v. 37, n. 1, p. 107-117, 2013.

CETESB - COMPANHIA ESTADUAL DE TECNOLOGIA DE SANEAMENTO BASICO E DE DEFESA DO MEIO AMBIENTECETESB. Relatório de Qualidade das Águas Interiores do Estado de São Paulo. São Paulo: CETESB, p.264, 2003.

CONSELHO NACIONAL DO MEIO AMBIENTE - CONAMA. Resolução n. 357, de 17 de março de 2005. Dispõe sobre a classificação das águas doces, salobras e salinas do território nacional. Diário Oficial da União, Brasília, 17 mar. 2005.

LIMA, S. L., IZARIO FILHO, H. J., CHAVES, F. J. M. Determinação de demanda bioquímica de oxigênio para teores $\leq 5$ mg. L $^{-1}$ O2. Revista Analytica, p.52-57, n.25, 2006.

MANOEL, L. O. Avaliação da qualidade da água na microbacia do córrego Caçula no município de Ilha Solteira-SP. 2013. 160p. Dissertação (Mestrado) - Faculdade de Engenharia Civil na área de recursos hídricos e tecnologias ambientais, Universidade Estadual Paulista - UNESP, Ilha Solteira, 2013.

QUEIROZ, M. M. F., IOST, C., GOMES, S. D., BOAS, M. A. V. Influência do uso do solo na qualidade da água de uma microbacia hidrográfica rural. Revista Verde de Agroecologia e Desenvolvimento Sustentável, v.5, n.4, p. 200-210, 2010.

SARDINHA, D. S., CONCEIÇÃO, F. T., SOUZA, A. D. G., SILVEIRA, A. J. M., GONÇALVES, J. C. S. I. Avaliação da qualidade da água e autodepuração do ribeirão do meio, Leme (SP). Engenharia Sanitária e Ambiental, p. 329-338, 2008. 
SILVA, M. M. A. P. M., FARIA, S. D., MOURA, P. M. Modelagem da qualidade da água na bacia hidrográfica do Rio Piracicaba-MG. Engenharia Sanitária e Ambiental, v. 22, n. 1, 2017.

VASCO, N. A., BRITTO, F. B., PEREIRA, A. P. S., MÉLlO JÚNIOR, A. V, GARCIA, C. A. B., NOGUEIRA, L. C. Avaliação espacial e temporal da qualidade da água na sub-bacia do rio Poxim, Sergipe, Brasil. Ambi-Agua, Taubaté, v. 6, n. 1, p. 118-130, 2011.

VON SPERLING, M. Introdução à qualidade das águas e ao tratamento de esgotos. 2. ed. Belo Horizonte: Escola de Engenharia da UFMG, 1996.

VON SPERLING, M. Princípios do Tratamento Biológico de Águas Residuárias. 3. ed. Belo Horizonte: Departamento de Engenharia Sanitária e Ambiental/UFMG, Belo Horizonte, MG, 2005. 